\title{
Analysis of hypoxia-inducible factor alpha polyploidization reveals adaptation to Tibetan plateau in the evolution of schizothoracine fish
}

\author{
Lihong Guan ${ }^{1,2}$, Wei Chi ${ }^{3}$, Wuhan Xiao ${ }^{1}$, Liangbiao Chen ${ }^{4}$ and Shunping $\mathrm{He}^{1 *}$
}

\begin{abstract}
Background: Hypoxia-inducible factor (HIF) is a master regulator that mediates major changes in gene expression under hypoxic conditions. Though HIF family has been identified in many organisms, little is known about this family in schizothoracine fish.

Results: Duplicated hif-a (hif-1aA, hif-1aB, hif-2aA, and hif-2aB) genes were identified in schizothoracine fish. All the deduced HIF-a proteins contain the main domains (bHLH-PAS, ODDD, and TAD), also found in humans. Evidence suggests a Cyprinidae-specific deletion, specifically, a conserved proline hydroxylation motif LxxLAP, in the NODD domain of schizothoracine fish HIF-1aA. In addition, a schizothoracine-specific mutation was observed in the CODD domain of the specialized and highly specialized schizothoracine fish HIF-1aB, which is the proline hydroxylation motif mutated into PxxLAP. Standard and stochastic branch-site codon model analysis indicated that only HIF-1aB has undergone positive selection, which may have led to changes in function. To confirm this hypothesis, HIF-as tagged with Myc were transfected into HEK 293 T cells. Each HIF-1aB was found to significantly upregulate luciferase activity under normoxic and hypoxic conditions, which indicated that the HIF-1aB protein was more stable than other HIF-as.
\end{abstract}

Conclusions: All deduced HIF-a proteins of schizothoracine fish contain important domains, like their mammalian counterparts, and each HIF-a is shorter than that of human. Our experiments reveal that teleost-specific duplicated hif-a genes played different roles under hypoxic conditions, and HIF-1aB may be the most important regulator in the adaptation of schizothoracine fish to the environment of the Tibetan Plateau.

Keywords: HIF-a, Schizothoracine fish, Hypoxia, Positive selection, Tibetan Plateau adaptation

\section{Background}

Gene duplication was first proposed by Bridges in 1936 in a study of the fruit fly Drosophila melanogaster [1]. It was further detailed by Ohno in a book, Evolution by Gene Duplication, in 1970 [2]. The ancestor of vertebrates experienced two rounds of whole-genome duplication which may have played a key role in adaptive evolution of vertebrate [2-5]. The third round of whole-genome duplication that occurred in teleosts is thought to have driven the diversification of teleosts [6-9].

Oxygen is critical to all aerobic life, particularly for animals living in water, which contains only $1 / 30$ th the

\footnotetext{
*Correspondence: clad@ihb.ac.cn

'Institute of Hydrobiology, Chinese Academy of Sciences, Wuhan, Hubei, P. R. China

Full list of author information is available at the end of the article
}

oxygen of air at the same partial pressure [10-13]. Sophisticated cellular mechanisms have evolved to allow organisms to detect and react to changes in oxygen levels. In these mechanisms, oxygen acts as the terminal electron acceptor in the mitochondrion of metazoans $[11,14,15]$. When studying the expression of EPO from Hep3B cells under hypoxic conditions, Semenza and Wang [16] identified a nuclear factor bound to the hypoxia-inducible enhancer (HIE) of the erythropoietin (EPO) gene at a site required for hypoxia activation of transcription. This nuclear factor was named hypoxiainducible factor (HIF). In mammals, HIF mediates major changes in gene expression under hypoxic conditions and participates in a series of processes including angiogenesis, erythropoiesis, glucose and iron transport, glycolysis, and cell-cycle control [11,17-21]. HIF is a heterodimeric 
transcription factor of the bHLH-PAS (basic helix-loophelix-per-ARNT-sim) family. It consists of an erratic alpha subunit (such as HIF-1 $\alpha$ ) and a steady beta subunit (such as HIF-1 $\beta$ or ARNT) [11,19,22-26]. According to studies in Caenorhabditis elegans and D. melanogaster, there is only one HIF- $\alpha$ in invertebrates, but in vertebrates, there are at least three functional HIF- $\alpha$ isoforms: HIF- $1 \alpha$, which regulates the acute hypoxic response; HIF- $2 \alpha$, which regulates the chronic hypoxic response; and HIF$3 \alpha$, which inhibits the activities of the other two isoforms $[11,14,19,20,27,28]$. HIF- $1 \alpha$ and HIF- $2 \alpha$ both have two oxygen-dependent degradation domains (NODDD and CODDD) that are located in the central region, and two transactivation domains-an inner activation domain (N-TAD) that overlaps with the CODDD and a carboxy-terminal activation domain (C-TAD). HIF- $3 \alpha$ lost the C-TAD [14,19,22,29]. With adequate oxygen (normoxia), one or both of the highly conserved prolyl residues located in ODDD of HIF- $\alpha$ (HIF- $1 \alpha$ and HIF$2 \alpha$ ) becomes hydroxylated by the prolyl-4-hydroxylase (PHD), and then the hydroxylated HIF- $\alpha$ interacts with the von-Hippel-Lindau tumor suppressor (VHL) and recruits ubiquitin ligase, which is consequently degraded by the proteasome [19,22,30,31]. However, under hypoxic conditions, HIF- $\alpha$, which is stabilized, translocates to the nucleus via its nuclear localization signal (NLS) motif, where it dimerizes with HIF- $\beta$ into HIF heterodimer and binds to the core DNA motif (G/ACGTG) in hypoxiaresponse elements (HREs) for transcriptional activation of the target genes [19,22,32,33].

The teleost-specific whole-genome duplication that occurred early in the teleost evolution generated six hif- $\alpha$ genes: $1 A / B, 2 A / B$, and $3 A / B$, which was followed by the loss of one member of each $A / B$ paralogous pair in most euteleosts but not in cyprinids [20]. The schizothoracine fish (Teleostei: Cyprinidae), which are divided into three groups (primitive, specialized, and highly specialized) according to the differences in their scales, pharyngeal teeth, and barbels, are the endemic and most diverse group of cyprinids distributed in the Tibetan Plateau and its adjacent areas. The elevation in this area ranges from 700 to $5000 \mathrm{~m}$, and the environment is characterized by hypoxia and low temperatures [34-36]. Primitive schizothoracine fish including Schizothorax, Schizocypris (not found in China), and Aspiorhynchus, are distributed at the edge of the Tibetan Plateau. Specialized schizothoracine fish included Diptychus, Ptychobarbus, and Gymnodiptychus, and highly specialized schizothoracine fish included Gymnocypris, Oxygymnocypris, Schizopygopsis, Platypharodon, Chuanchia, and Herzensteinia. The distribution of specialized and highly specialized schizothoracine fish is largely limited to the central region of the plateau [37]. Each group represents specific periods of geological evolution of the Tibetan Plateau, which ultimately caused the modern distribution pattern of schizothoracine fish, in which primitive, specialized, and highly specialized schizothoracine fish are distribued from the edges to the central part of the plateau (Figure 1) [35]. Previous analyses of the mitochondrial genome have demonstrated that schizothoracine fish, which are teleost fishes, are well-adapted to high altitudes and hypoxia [38]. However, hif- $\alpha$ genes, which are related to hypoxia, have been little studied in schizothoracine fish. Chi [12] referred to the evolutionary patterns of the hif- $\alpha$ genes in two high-altitude fish, but no signs of adaptive evolution was detected since the species limitation.

To better understand the relationship between adaptation to hypoxia and $h i f-\alpha$ genes in plateau and plains fish, teleost-specific hif- $\alpha$ gene duplications (hif- $1 \alpha A / B$ and hif-2 $\alpha A / B$ ) were cloned and identified in six species of schizothoracinae and in zebrafish. Further computational and experimental analyses reveal the mode of evolution and response to hypoxia of these gene paralogs.

\section{Results}

\section{Characterization of hif- $a$ duplications and phylogenetic analysis}

Although many studies have focused on HIF in cyprinids, duplicated HIF- $\alpha$ paralogs have never been identified in schizothoracine fish. The sequences of hif- $\alpha$ paralogs (hif$1 \alpha A / B$ and hif-2 $\alpha A / B)$ of the six species of schizothoracinae were obtained here for the first time [GenBank: KJ679876-KJ679899]. The N-terminal of zebrafish hif-1 $\alpha A$ sequence was also isolated [GenBank: KJ679875]. The data sets supporting the results of this article are also available in the Dryad Digital repository [39]. The lengths of different hif- $\alpha$ paralogs in schizothoracine fish were found to vary. However, the lengths of specific hif- $\alpha$ genes remained consistent among highly specialized schizothoracine fish, even when the schizothoracine fish came from different genera (Additional file 1: Table S1).

Protein analysis showed that HIF- $\alpha$ paralogs from schizothoracine fish all contained the main domains, like their mammalian counterparts. The similarity between duplicated HIF- $1 \alpha \mathrm{A}$ and HIF- $1 \alpha \mathrm{B}$ was $52 \%$, and the similarity between duplicated HIF- $2 \alpha \mathrm{A}$ and HIF- $2 \alpha B$ was $55 \%$. The bHLH-PAS domain of HIF- $\alpha$ s N-terminal was highly conserved, but the C-terminal was less conserved, especially near the oxygen-dependent proline hydroxylation sites. A deletion, specifically, the conserved proline hydroxylation motif LxxLAP, was detected in the NODD domain of HIF- $1 \alpha \mathrm{A}$ in all six schizothoracine fish and zebrafish (Figure 2 and Additional file 2: Figure S1 A). Currently, hif-1 $\alpha A$ was only amplified in Cyprinidae, so this deletion might be Cyprinidae-specific. Sequence alignment suggested that there was a schizothoracine-specific mutation in the CODD domain of the HIF- $1 \alpha B$ of 


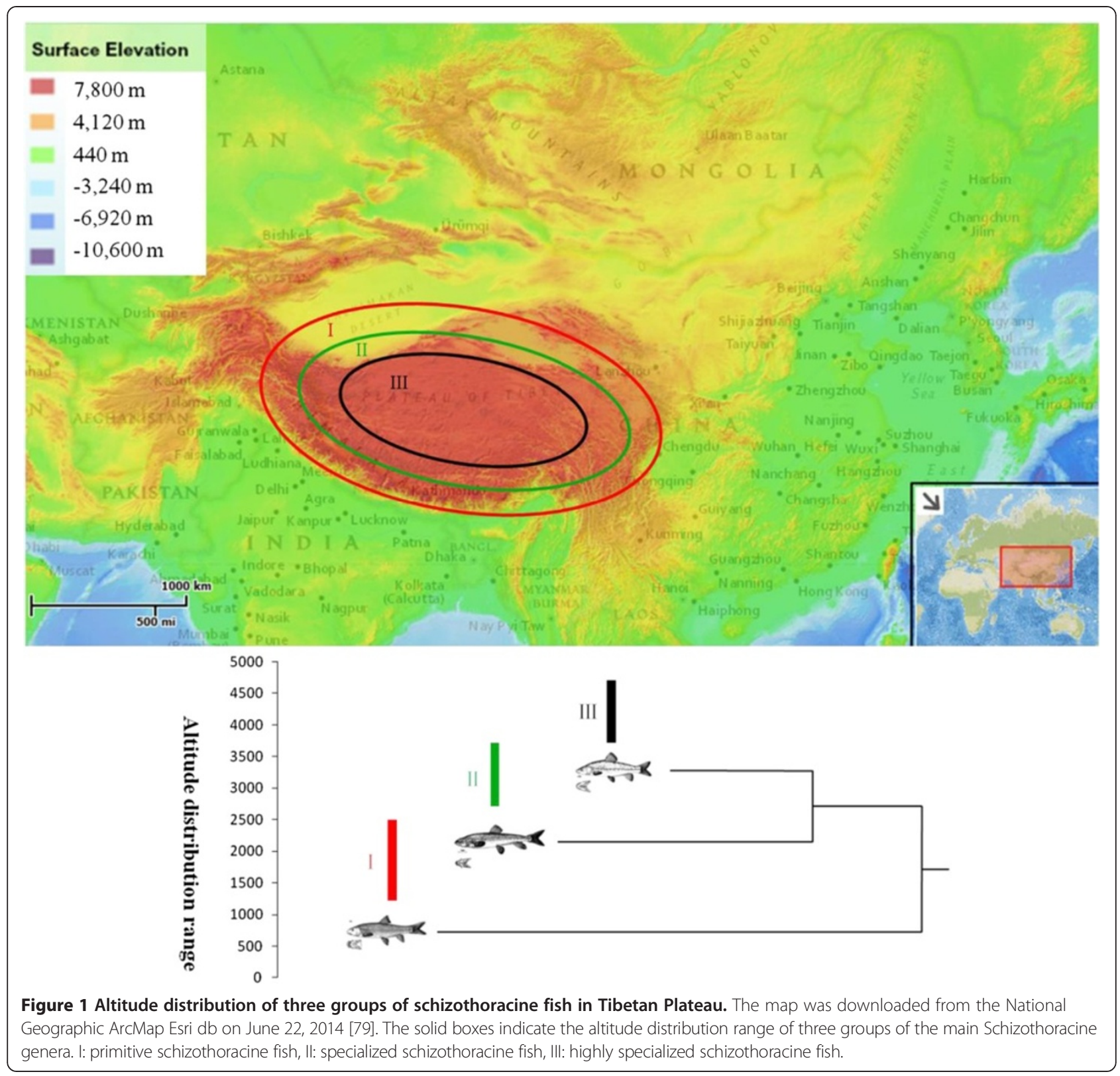

specialized and highly specialized schizothoracine fish, specifically the proline hydroxylation motif mutated into PxxLAP (Figure 2 and Additional file 2: Figure S1 B). All deletions and mutations were located in functional ODD domains that interacted with PHD via the PHD-HIF oxygen-sensing system $[11,22,40]$. This may affect function during biological processes. The targets of PHD in mammals are proline 402 and proline 564 in the ODD domain, but Pro-564 is the primary critical substrate in PHD binding to HIF-1 $\alpha$ [10,41]. It is here speculated that HIF- $1 \alpha B$ is more likely to change function than other HIF- $\alpha$ s are.

The chordate phylogenetic tree of hif- $1 \alpha$ and hif- $2 \alpha$ genes was reconstructed using the MrBayes and RAxML softwares with sea squirt and amphioxus hif- $\alpha$ sequences as the outgroups $[42,43]$. The two computer programs inferred similar tree topologies. The Bayesian posterior probability values and maximum likelihood bootstrap values were high (Figure 3, Additional file 3: Figure S2). The topology was largely consistent with that found in previous studies $[11,29]$. However, the phylogeny estimated for the hif-1 $\alpha$ gene was inconsistent with the recently published hif- $1 \alpha$ phylogenies based on the PhyloBayes [44] and RAxML softwares [20]. Recent results indicated a sister relationship between hif-1 $\alpha A$ and hif- $1 \alpha B$, our results indicate instead that hif- $1 \alpha B$ might be more similar to the ancient hif- $1 \alpha$ than hif- $1 \alpha A$ is. Massey et al. [45] and Roje [46] have researched on the 
A

Homo_sapiens_hifla Danio rerio 1.

Hypophthalmichthys_molitrix_1A

Hypophthalmichthys_nobilis_ $\overline{1} A$

Schisothorax_prenanti_1A

Gymnodiptychus_pachycheilus_1A

Gymnocypris eckloni 1A

Gymnocypris namensis $1 \mathrm{~A}$

Schizopygopsis_pylzovi_A

Platypharodon_extremus_1A

Hemiscyllium ocellatum 1

Acipenser sinensis 1

Acipenser_gueldenstaedtii_1

Lepisosteus platostomus 1

Onyzias latipe

Polyodon_spathula_1

Polypternis_senegalus_1

Takifugu rubripes 1

Danio rerio 15

Hypophthalmichthys molitrix 1

Hypophthalmichthys_nobilis_ $\overline{1}$

Ctenopharyngodon idella 1

Carassius carassius 1

Megalobrama_amblycephala_1

Myxocyprinus_asiaticus_1

Schizothorax prenanti 15

Gymnodiptychus pachycheilus_1B

Gymnocypris_eckloni_1B

Gymnocypris_namensis_1B

Gymnocypris przewalskii 1

Schizopygopsis pylzovi $\overline{1 B}$

Platypharodon extremus $1 B$

B

Homo_sapiens_hifla

Danio rerio $1 \mathrm{~A}$

Hypophthalmichthys molitrix $1 \mathrm{~A}$

Hypophthalmichthys_nobilis_ $\overline{1}$ A

Schizothorax_prenanti_1A

Gymnodiptychus pachycheilus_1A

Gymnocypris eckloni 1 A

Gymnocypris_namensis_1A

Schizopygopsis pylzovi_1A

Platypharodon extremus 1 $\mathrm{A}$

Hemiscyllium ocellatum

Acipenser_sinensis_1

Acipenser_gueldenstaedtii_1

Lepisosteus platostomus I

Oryzias latipe

Polyodon_spathula_1

Polypterus_senegalus_1

Takifugu_rubripes_1

Danio rerio $1 B$

Hypophthalmichthys_molitrix_1

Hypophthalmichthys nobilis 1

Ctenopharyngodon idella 1

Carassius carassius 1

Megalobrama_amblycephala_1

Myxocyprinus_asiaticus_1

Schizothorax prenanti 15

Gymnodiptychus_pachycheilus_1B

Gymenocypris_eckloni_1B

Gymnocypris_namensis_1B

Gymnocypris przewalskii 1

Schizopygopsis_pylzovi_ $\overline{1 B}$

Platypharodon_extremus_1B

L $x \times$ L A P

K - VESEDT S L F DKLKKEP DAL T L L A PAA GDT I I SLDFGS N D E T D D 422

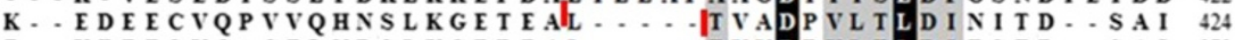

E - K E E E S V G - G E L ND S L K G E P E ALL . . . T V VDP VL T L D I T S T D . S A I 379

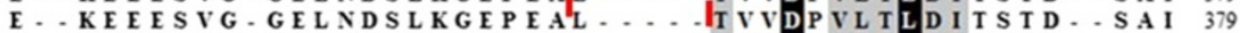

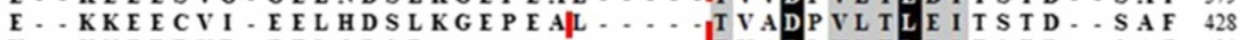

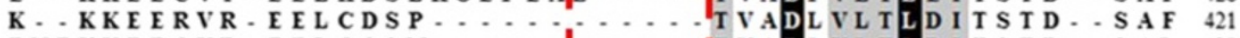

E NEKKE E C VR . E E L C G S M ............. IT V ADL V L T L D I T S T D . SA L 423

E NEKKEECVR E E L CDS M .......... T VADL VL TLD I T S T D . S A L 423

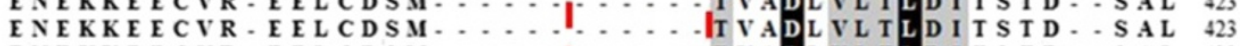

E NEKKE E C VR. E E L C D S M . . . . S A L 423

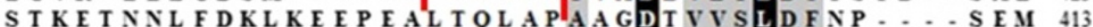
QVDPEENT NSL FEKLKEEPEAlLTLLA PIA A GDT I I S L D F S K S D N - S E I 423 QVDPEE NT NSL FEKLKEEPEAL T L L A PA A GD I I I S L D F S K S D N - S E I 423 KA E D L E S S N T L F E KL KE E P E AL T L L A P|A A GD T I I S L D F T S S D - - S E I 421 T L Y DQLKE E P E AL T L L A PAA GDT I I S L D F S Q P E - P E I 325 QVDPEEST NSLFEKLKEEPEALTLLAPIA A GDT I I SLDFSKS D - S E I 423 K T VPEG D GDS L F D K L K E E P E AlL T V L A P A A GD T I I S L D F S T - T E S E M 422 EVTE S Q P V S S L Y DKLK E K P E AL T L L A PA A G D T I I S L D F S C P D - . S E M 432 L N.CSLES S T L Y NKLKE EP E AL T VLA PIA A GDA I I SLD F N N S D. - S D I 432 L K - C P ME C S D Y Y QLKE E P E AL T L L A PAA GDT I I SLD F N N S D. . S D M 430 LK - C P ME CS D L Y E QLKEEPEAL T L L A PLA A GD T I I S L D F N N S D - S D M 430 LK - C P ME C S D YEQLKE E P ALL T VL A PA A GDT I I SLD F N N D - S D M 430 LK - CPVKS S ELYEKLKE EPEAL NVLAPISA GDT I I SLDFNNS D. . S D M 430 L K - C P ME C S D L Y Q L KE E P E AlL T V L A P|A A GDT I I S L D F N N S D. . S D M 430 L K H CKE S S S S L Y E KLKEQP E ALA G LA PA A GDT I I S L D F N N S D. S D V 432 LK - C P MKS S D L Y DLKE E PAL T VL A PLA A GD I VI SLD F N N D - S DM 430 L G - C PKK S P D L Y EKLKE E P E SIL T VL A PAA GDT I I SLD F N N S D . . S D M 430 LK - C P MKNLDL Y EKLKEDS EAL T VLA PlA A GDT I I S L D F N N S D. . S D M 430 LK - CPMKNL D L Y E KLKE DS E AlL T VLA P|A A GD T I I S D D N N S D - S D M 430 LK - CPMKNL D L Y KLKE DS E AL T VLA PA A GDT I I SLD F N N D - S D M 430

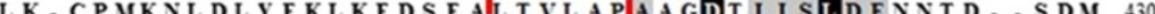
LK - CP MKNL D L Y ELKE DSEAL T VLA PAA GDT I I SLD F N N D - S D M 430

\section{LXXLAP}

VD S D M N N F KL E L VEK L FA EDT EA K N P F S T QD T D - L D L EMLA P Y I P M D D D V D S E L C D Q L K P D HV E K HF S MD I E S K T . . . Q G V G - L D L E ML A P Y I P M D D D VDS E L S D Q L K P D HV E R L F S MDMES K T H F K T Q G V G - L D L E ML A P Y I P M D D D VDS E L S D Q L K P D H V E R L F S MDMES K T H F K T Q G V G - L D L E MLA P Y I P M D D D V D S E L S D Q L K P D H V E R L F S M D I E S K T P F N T Q G V G - L D L E M VDS E L S D Q L K P D QV ER L F S MD I ES K T H F N T QG V G - L DLL MLA P Y I P M D D D VDS E L S D Q L K P D HV ER LFS MDIES K T P F T QG V G - L D L E MLA PY I P M D D D VDS E L S D Q L K P D H V E R L F S MD I E S K T P F N T Q G V G - L D L E ML A P Y I P V D S E L S D Q L K P D H V E R L F S MD I E S K T P F N T Q G V G - L D L E M L A P Y I I P VDS E L S DQLKP D HV ER LFS MDIESKT P F N T QG V G - L D LE MLA PY I P MD D D VDT D I S NE FKL D I V EKL FA I DPFA K H P F S VOD I D N L DL E MLA P Y I P M D D D VE T D F S G E F K M D L V E K L F A I D T E E A T P F T T Q VE T D F S G E F K M D L V E K L F A I VDS D I G S E F KL D L V EKL F A I D T EA K T P F A T QT MD D L D L E MLA P Y I P M D D D

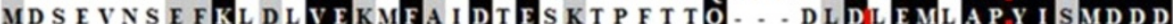

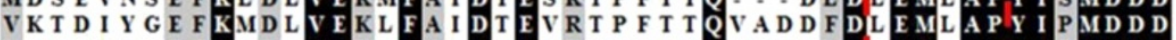

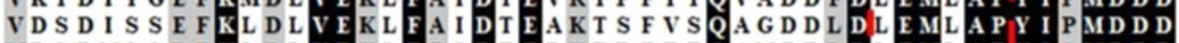
MDS DMS S D FKL D L V EKL F I I D T EP K T P F T T QAME D L DL E MLA P Y I S M D D D VE P D I S S E F K L D L V E K L F A I DTEAKT P F S T OP ME D L D L E MLA P Y I P M D D D V D S D I S S E F K L D D L V E K L L F A I

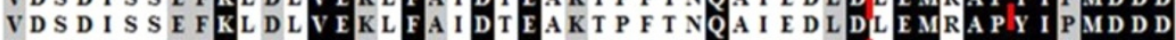
VDS D I S S E FKL D L V EKLFA I D T E A K T P F T NQA I E D L D L E MLA PY I P M D D D VDS D I S S E F K L D L V E K L F A I D T E A K T P F S S QA ME D L DLLE MLA P Y I P M D D D VDS D I S S E F K L D L V E K L F A I VDS D I S S E F K L D L V E K L F A I VDSD I S S E FKL D LV EKLFA I DTEAKT P F S S QAME D LDLE MLA PY I P M D D D VD.. IS S E F K L D L V F K MF A N D T E A K T P F S S Q A M E D L D P F M L A P Y I P M D D D

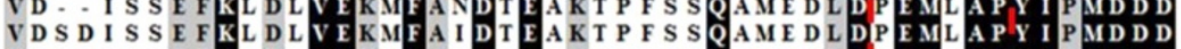
VDS D I S S E F K L D L V E K MFA N D T E A K T P F S S Q A M E D L D P E MLA P Y I P M D D D VDSDISSE FKLDLVEKMFA NDTEAKT P F S QAMEDLDM E MLA PY I PID D VDS D I S S E F K L D L V E K M F A N D T E A K T P F S S S Q A M E D L D D P E MLA A P Y I I P M D D D

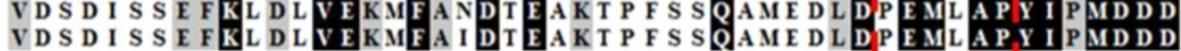

\section{533
491
491
543
536
538
538
538
538
562
564
564
566
445
564
567
554
564
562
562
562
562
562
562
562
560
562
562
562
562
562}

Figure 2 Partial multiple sequence alignment of the deduced HIF-1a protein sequences. A) In Cyprinidae, HIF-1aA proteins were found to have a deletion (LxxLAP) in the conserved NODD domain. B) Specialized and highly specialized schizothoracine fish were found to have a mutation ( $L x x L A P$ to PxxLAP) in the conserved CODD domain of HIF-1aB. Dashes indicate that the gaps inserted for facilitated alignment. The two conserved proline hydroxylation motif LxxLAP are indicated by the dotted boxes.

effects of non-neutral gene on phylogeny. In this study, more hif- $1 \alpha B$ sequences were used than any other studies, which might have led to a non-synonymous to synonymous rate ratio $(\mathrm{dN} / \mathrm{dS})$ distinct from that obtained in previous studies. The phylogeny (Additional file 4: Figure S3 A) in the schizothoracine fish constructed 


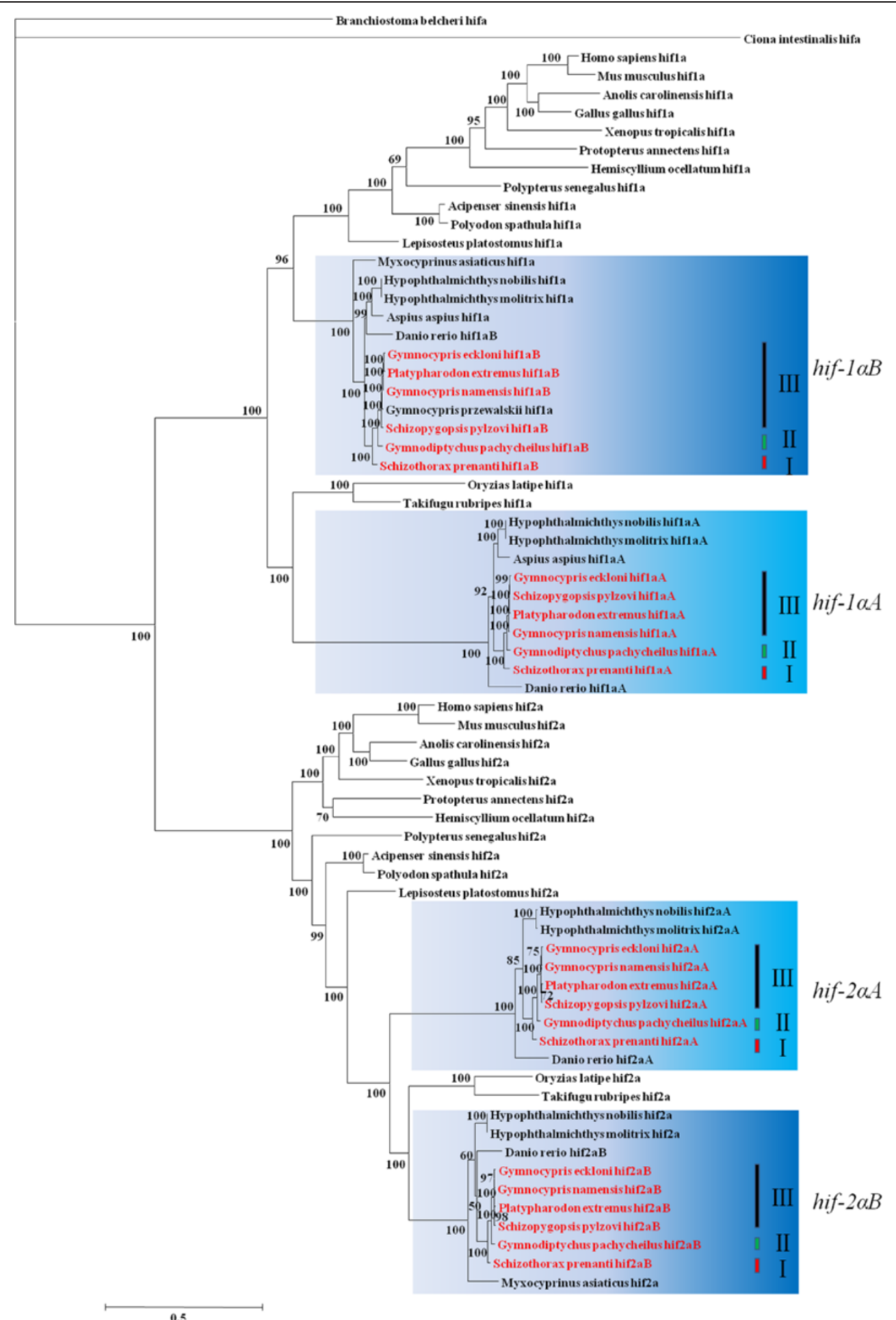

Figure 3 Phylogenetic tree was constructed for the selected chordate hif-1a and hif-2a genes. The phylogenetic tree was constructed using MrBayes with GTR + I (0.0821) + G (1.0813) modes. To search tree space, Markov chain Monte Carlo (MCMC) simulations were performed for 2,000,000 generations with parameter sampling every 1,000 generations. The first 1,000 samples were discarded during the burn-in phase of the MCMC analysis. The Bayesian posterior probability values are indicated beside the branches. 
using concatenated hif- $1 \alpha$ and hif- $2 \alpha$ sequences agrees with that using mitochondrial cytochrome $b[38,47]$. For this reason, it was considered suitable for use in the following selection pressures analysis.

\section{Molecular evolution of the teleostei HIF-a duplicate}

First, standard branch-site models in PAML [48] were used to assess the different selective pressures experienced by the protein coding sequences of each HIF- $\alpha$ paralogous pair. In this model, the foreground branches are the branches tested for positive selection, and the background branches are all other branches on the tree [48]. In the likelihood ratio test (LRT), branch-site model $\mathrm{A}$ is the alternative model allowing $\omega_{2}$ to vary among codons, while the simpler null model is model A but with $\omega_{2}=1$ fixed [48]. In this study, three methods were used to specify the foreground branches. According to the LRT of branch-site models, for HIF-1 $\alpha B$, when the clade of all schizothoracine fish was specified as the foreground branches, the likelihood obtained under model A was not significantly higher than that obtained under the null hypothesis of no positive selection; but when the clade of specialized and highly specialized schizothoracine fish was specified as the foreground branches, the likelihood obtained under model A was significantly higher than that of the null model $(2 \Delta \ln L=12.16, p<0.01, d f=1)$ and $\omega>1 \quad(\omega=7.11$, Table 1$)$. When only the clade of highly specialized schizothoracine fish was specified as the foreground branches, the likelihood obtained under model A was quite significantly higher than that of the null model $(2 \Delta \ln L=19.79, p<0.01, d f=1)$ and $\omega>1$ $(\omega=23.24)$ (Table 1$)$. The posterior probability of sites that had undergone positive selection was calculated using the Bayes empirical Bayes (BEB) method in model A. For these last two analyses, there were 9 and 10 amino acid sites in $H I F-1 \alpha B$ sequences with a posterior probability greater than 0.5 . In the second method, the amino acid sites at position 464 (according to HIF-1 $\alpha B$ of $D$. rerio) had a posterior probability 0.990 as indicated by BEB, which was significant at the $1 \%$ level, but in the third method, the amino acid sites at position 387 and 510 had a posterior probability 0.989 and 0.987 as indicated by BEB, which was significant at the $5 \%$ level. In this way, they were identified as crucial amino acid sites that had experienced positive selection. Three of the 9 sites and 4 of the 10 sites were located in the ODD domain by the last two methods. For $H I F-1 \alpha A, H I F-2 \alpha A$, and $H I F-2 \alpha B$, no other positively selected site was detected.

Secondly, stochastic branch-site models in fitmodel [49] were used to detect the different selective pressures experienced on the protein coding sequences of $H I F-1 \alpha$ and $H I F-2 \alpha$, respectively. For $H I F-1 \alpha$, the likelihood obtained under M3 + S1 $(\omega 2=8.7857)$ model was significantly higher than that obtained under null $(\mathrm{M} 1+\mathrm{S} 1)$ model with $\omega 2>1$ and $2 \Delta \operatorname{lnL}=6.29(\mathrm{p}<0.05)$. However, there were only 3 amino acid sites $(77 \mathrm{~K}, 395 \mathrm{~S}$, and $398 \mathrm{~L}$, according to $H I F-1 \alpha B$ of $D$. rerio) with a posterior probability $>0.5$. For $H I F-2 \alpha$, no other positively selected site was detected.

In standard branch-site models, although the foreground branches specified for $H I F-1 \alpha B$ were different, the last two methods showed similar positively selected sites with different levels of significance. With stochastic branch-site models, positive selection was also detected in $H I F-1 \alpha A$ and $H I F-1 \alpha B$. It is here hypothesized that the $H I F-1 \alpha B$ experienced strong selective pressure, which may have led to changes in function. The higher the altitude at which the schizothoracine fish were distributed, the more significant the selective pressure was. This may be one of the mechanisms by which schizothoracine fish have adapted to the high altitudes of the Tibetan Plateau.

\section{Expression and hypoxic regulation of different HIF-a paralogs in HEK 293 T cells}

RytKönen [20] showed that the transcription of hif-1 $\alpha$ decreased after hypoxic insult in adult zebrafish, but the transcription of hif- $2 \alpha A$ remained stable and hif- $2 \alpha B$ transcription increased significantly. To determine whether changes in oxygen tension regulate HIF- $\alpha$ at the protein level, HEK 293 T cells were transfected with either the indicated Myc-tagged HIF- $\alpha$ constructs or an empty vector, and cells were subjected to $18 \mathrm{~h}$ of hypoxic treatment after $6 \mathrm{~h}$ of normoxic cultivation. Western blot analysis indicated that all the fish HIF- $\alpha$ s could be expressed in HEK 293 T cells. Compared to the normoxic condition, there were only rarely significant increases in levels of protein expression under hypoxic conditions: HIF-1 $\alpha \mathrm{A}$ and HIF- $1 \alpha \mathrm{B}$ in D. rerio, HIF- $1 \alpha \mathrm{B}$ in Gd. pachycheilus and

Table 1 Positively selected sites detected in HIF-1aB of specialized and highly specialized schizothoracine fish by branch-site models

\begin{tabular}{|c|c|c|c|}
\hline Foreground branch & $\Delta \ln L$ & Parameter estimates & Positive sites \\
\hline $\begin{array}{l}\text { specialized and highly specialized } \\
\text { schizothoracine fish }\end{array}$ & 6.08 & $p_{0}=0.820 p_{1}=0.149 p_{2}=0.026 \omega_{0}=0.074 \omega_{1}=1 \omega_{2}=7.113$ & $\begin{array}{l}\text { 215P 370E } 371 \text { T 386P 387E } 3965 \text { 464D } \\
\text { 510D 534I }\end{array}$ \\
\hline highly specialized schizothoracine fish & 9.89 & $p_{0}=0.820 p_{1}=0.17 p_{2}=0.010 \omega_{0}=0.079 \omega_{1}=1 \omega_{2}=23.246$ & $\begin{array}{l}\text { 41H 370E } 371 \mathrm{~T} 386 \mathrm{P} 387 \mathrm{E}^{*} 428 \mathrm{~S} 464 \mathrm{D} \\
467 \mathrm{P} 510 \mathrm{D}^{*} 648 \mathrm{~T}\end{array}$ \\
\hline
\end{tabular}


HIF-2 $\alpha$ A of G. eckloni (Figure 4). Generally, the expression level of HIF- $1 \alpha$ was greater than that of HIF- $2 \alpha$ after hypoxic treatment and under normoxic conditions (Additional file 5: Figure S4).

To determine whether selective pressure could have affected the transcriptional activity of HIF- $\alpha$ toward their common targets, empty vector (control) and the indicated Myc-tagged HIF- $\alpha$ constructs were co-transfected with the HRE-luciferase reporter and pTK-Renilla luciferase in HEK 293 T cells. Each HIF- $1 \alpha$ and HIF- $2 \alpha$ was found to upregulate luciferase activity under normoxic conditions (Figure 5). This indicated that the function of fish HIF- $\alpha$ s had been conserved. In addition, HIF- $1 \alpha B$ showed more luciferase activity than other HIF- $\alpha$ s, even under normoxic conditions, suggesting that HIF- $1 \alpha B$ protein may be more stable. The transcriptional activity of HIF- $2 \alpha$ was obvious under normoxic conditions but not detectable under hypoxic conditions.

\section{Discussion}

Fish possess homologs of HIF- $\alpha$ and HIF- $\beta$ that share strong similarity with those of humans. They may play roles similar to those of their mammalian counterparts in expression of oxgen-dependent genes [13]. The sequence of hif- $\alpha$ gene had been extensively characterized in fishes. The first fish hif- $\alpha$ gene was identified in rainbow trout (Oncorhynchus mykiss) in 2001 [50]. The sequence was slightly shorter than that of mammals. It included bHLH-PAS and ODD domains and proline and asparagine residues, which were relatively conserved in the deduced rainbow trout HIF- $\alpha$ protein. Subsequently, hif- $\alpha$ gene was reported from killfish (Fundulus heteroclitus), grass carp (Ctenopharyngodon idellus), crucian carp (Carassius carassius), zebrafish (Danio rerio), Atlantic croaker (Micropogonias undulatus), asp (Aspius aspius), three-spined stickleback (Gasterosteus aculeatus), Russian sturgeon (Acipencer gueldenstaedtii), naked carp (Gymnocypris przewalskii), Wuchang bream (Megalobrama amblycephala), Chinese sucker (Myxocyprinus asiaticus), bighead carp (Hypophthalmichthys nobilis), silver carp (Hypophthalmichthys molitrix), Prenant's schizothoracin (Schizothorax prenanti), Namucuo naked carp (Gymnocypris namensis), and so on [10,12,51-58].

Although previous studies identified HIF- $\alpha$ in schizothoracine fish, the present study is the first to identify teleost-specific duplicated HIF- $\alpha$ paralogs. It not only provides new information for HIF research in teleosts but also supplies a foundation for further study of the adaptation of schizothoracine fish to high altitudes and low oxygen levels in the Tibetan Plateau. Each schizothoracine fish HIF- $\alpha$ was smaller than the corresponding human HIF- $\alpha$. The HIF- $1 \alpha \mathrm{A} / \mathrm{B}$ and HIF- $2 \alpha \mathrm{A} / \mathrm{B}$ of

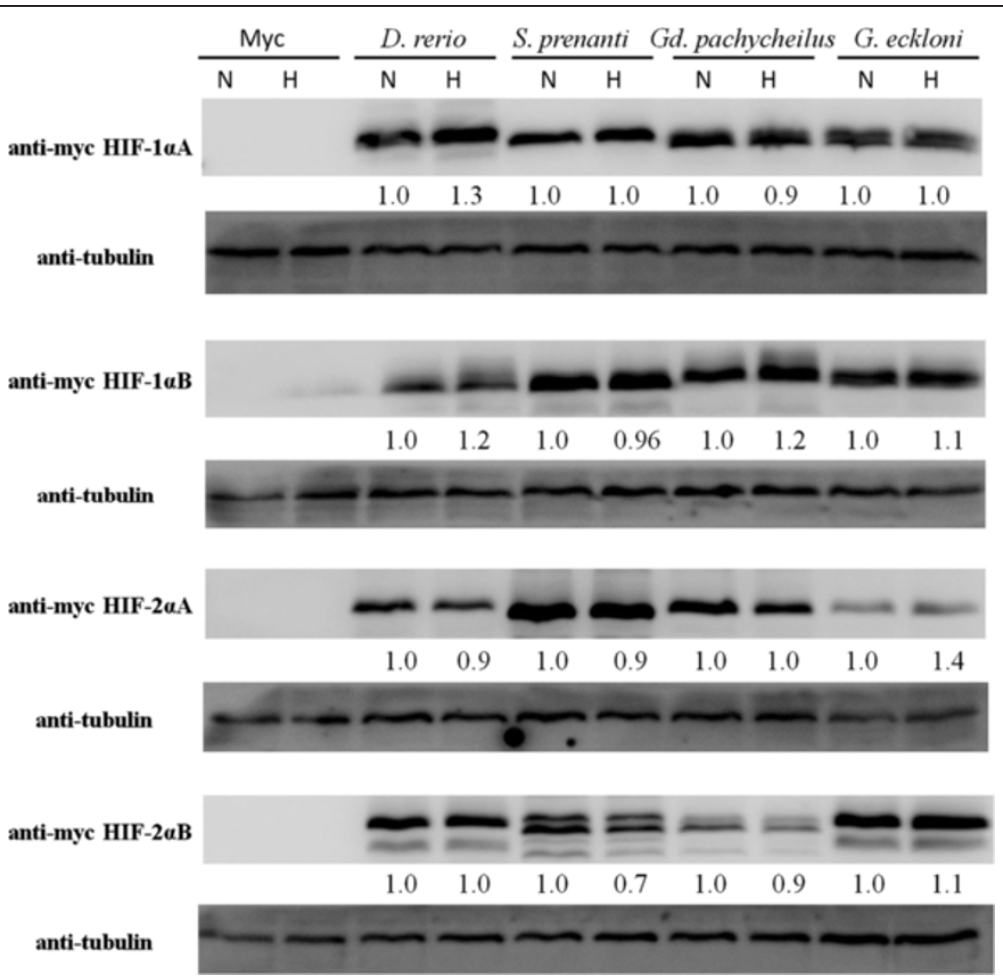

Figure 4 Expression of HIF-a in HEK 293 T cells under normoxic and hypoxic conditions. N: normoxia, H: hypoxia. There was no significant different in protein expression levels under hypoxic and normoxic conditons, excepting that there was more expression of HIF-1aA and HIF-1aB of D. rerio, HIF-1aB of Gd. Pachycheilus and HIF-2aA of G. eckloni under hypoxic conditions. 


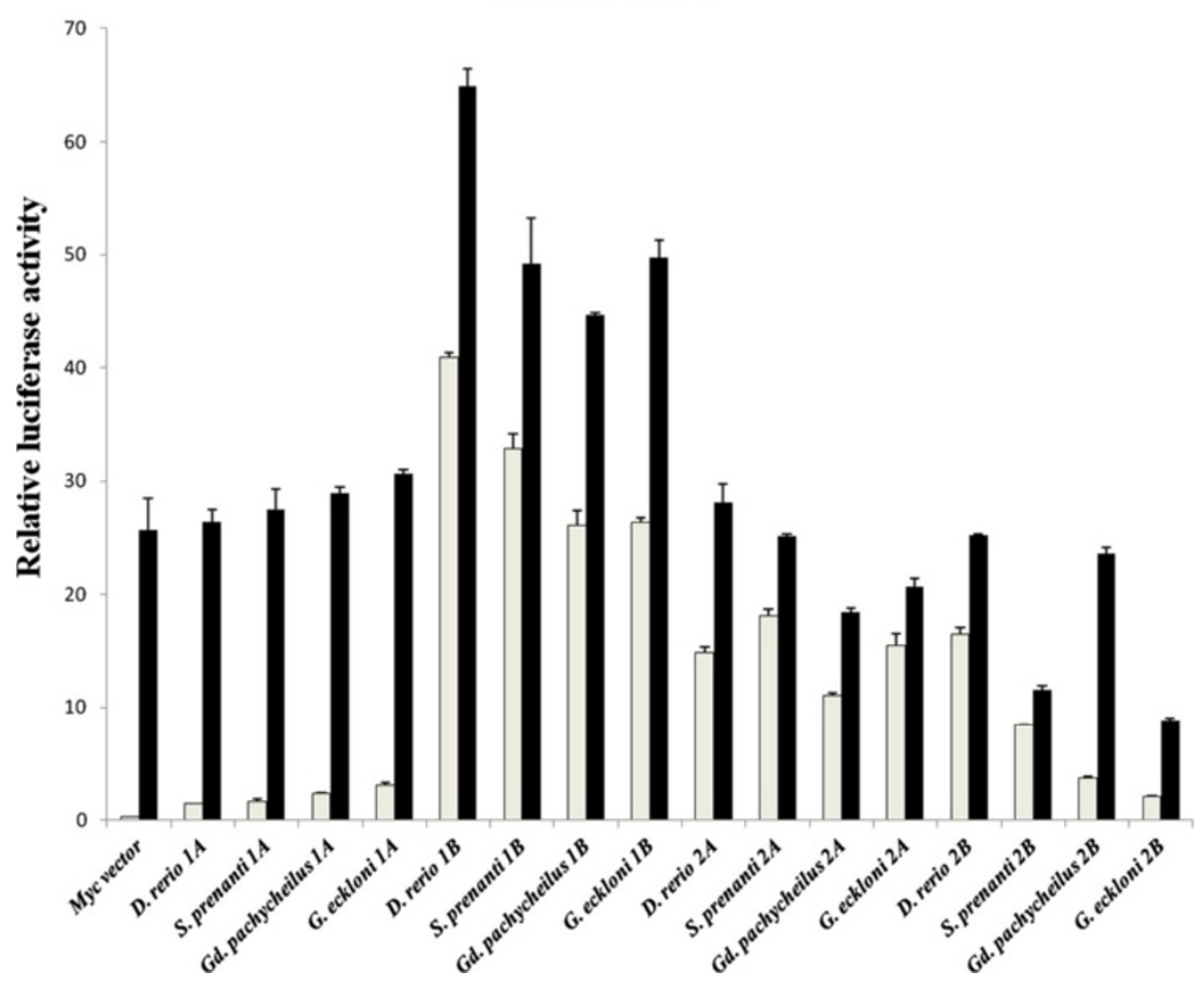

Figure 5 Transcriptional activity of HIF-as under normoxic and hypoxic conditions. Each HIF-1a and HIF-2a was found to upregulate luciferase activity under normoxia, and the luciferase activity of HIF-1aB was high even under normoxia.

schizothoracine fish shared more than 46 and 53\% similarity with human HIF- $1 \alpha$ and HIF- $2 \alpha$, respectively. HIF- $1 \alpha B$ and HIF- $2 \alpha B$ shared more sequence identities with human HIF- $1 \alpha$ and HIF- $2 \alpha$ than HIF- $1 \alpha \mathrm{A}$ and HIF-2 $\alpha$ A did in all species except Gd. pachycheilus. The bHLH-PAS domain of HIF- $\alpha$ s N-terminal was highly conserved, but the ODD domain of the Cterminal was less conserved, especially in regions in the vicinity of the oxygen-dependent proline hydroxylation sites. A Cyprinidae-specific deletion (LxxLAP) in the NODD domain of HIF-1 $\alpha$ A may have occurred in all six schizothoracine fish, and a schizothoracine-specific mutation LxxLAP mutated to PxxLAP in the CODD domain of the specialized and highly specialized schizothoracine fish HIF- $1 \alpha \mathrm{B}$. The HIF hydroxylase pathway was regulated by the PHD family of oxygen-dependent prolyl hydroxylases in metazoans [19]. In mammals, the Pro-564 in the CODD domain is the primary critical substrate in PHD binding to HIF-1 $\alpha$ [31]. It was here deduced that although the deletion and mutation were all located in the ODD domain, the change in the CODD domain of HIF- $1 \alpha B$ was more important than the deletion in the NODD domain of HIF-1 $\alpha$ A was in the evolution of schizothoracine fish.

The HIF pathway plays a pivotal role in the response to hypoxia, and the PHD family of oxygen-dependent prolyl hydroxylases plays a critical role in regulating HIF stability [19]. Some candidate genes associated with the HIF pathway showed signals of positive selection in species living in the Tibetan Plateau. For instance, EPAS1 (HIF-2 $\alpha), E G L N 1$, and PPARA were detected in Tibetans [59,60]; ADAM17 in the yak [61]; ADORA2A, CCL2, ENG, PIK3C2A, PKLR, ATP12A, and NOS3 in the Tibetan antelope [62]; SRF, TXNRD2, and WNT7B in the ground tit [63]; and EPAS1, SIRT7, PLXNA4, and MAFG in the Tibetan mastiff [64]. In this study, computational estimation suggested that the specialized and highly specialized schizothoracine fish $H I F-1 \alpha B$ have experienced significantly selective pressure. Positively selected sites were detected in $H I F-1 \alpha, H I F-2 \alpha$, and $H I F-2 \alpha$, respectively in schizothoracine fish, Tibetans, and Tibetan mastiff. This shows that fish and mammals developed different mechanisms for adapting to the special environment of the Tibetan Plateau.

Functional analysis was performed by transfecting schizothoracine fish HIF- $\alpha$ in HEK 293 T cells. Results showed that the expression level of HIF-1 $\alpha$ differed from that of HIF-2 $\alpha$. Hypoxia was found to increase the abundance of HIF- $1 \alpha \mathrm{A} / \mathrm{B}$ but not that of HIF$2 \alpha \mathrm{A} / \mathrm{B}$. The decrease in the protein levels of HIF- $2 \alpha \mathrm{A} / \mathrm{B}$ may be attributable to the combined impact of the reduced protein synthesis under hypoxic conditions and 
the rapid folding rate of HIF- $\alpha$ protein in mammalian cells [65]. The luciferase assay showed that all the HIF- $\alpha \mathrm{s}$ characterized in this study were capable of forming functional heterodimers with human HIF- $\beta$ and could activate $\mathrm{HRE}$ reporter gene, but they performed different levels of oxygen-dependent regulation. Each HIF- $\alpha$ (HIF$1 \alpha \mathrm{A} / \mathrm{B}$ and HIF-2 $\alpha \mathrm{A} / \mathrm{B}$ ) was able to upregulate luciferase activity under normoxic conditions, and HIF-1 $\alpha \mathrm{B}$ was more significant, suggesting that HIF- $1 \alpha \mathrm{B}$ was more stable under normoxic conditions. The transcriptional activity of HIF-1 $\alpha$ B was higher than that of other HIF$1 \alpha$ s under hypoxic conditions, and transcriptional activity was stronger under hypoxic conditions than under normoxic conditions. These results were also supported by structural analysis. For HIF- $1 \alpha B$, the bHLH-PAS domain, which is responsible for heterodimerization with HIF- $\beta$ and DNA binding, was conserved; and the ODD domain, which interacts with PHD, was mutated [10,19,22,66,67]. It was also discovered that HIF- $2 \alpha \mathrm{A} / \mathrm{B}$ downregulated luciferase activity under hypoxic conditions. This was consistent with the decrease observed in protein levels of HIF- $2 \alpha \mathrm{A} / \mathrm{B}$ after hypoxia treatment.

\section{Conclusions}

The teleost-specific duplicated hif- $\alpha$ paralogs, hif- $1 \alpha A$, hif- $1 \alpha B$, hif- $2 \alpha A$, and hif- $2 \alpha B$, were successfully identified in schizothoracine fish. Each deduced HIF- $\alpha$ was found to have the same principal domains as its mammalian counterparts, and had evolved specialized roles in the response to hypoxia. It is here postulated that HIF- $1 \alpha B$ may be the most important regulator in the adaptation of schizothoracine fish to the environment of the Tibetan Plateau. Although sequence variation and significant selective pressure were detected in HIF- $1 \alpha B$ of the specialized and highly specialized schizothoracine fish, transcriptional activity showed no significant difference between plateau fish (schizothoracine fish) and plains fish (zebrafish). This might be because zebrafish are also hypoxia tolerant fish $[10,13]$. Further studies are needed to explore the structure and functions of schizothoracine fish HIF- $\alpha$ s and to determine their roles in the mechanism underlying the response to hypoxic conditions. The adaptation to Tibetan Plateau of schizothoracine fish involves a complicated evolutionary mechanism, which is affected by a cluster of genes. In the future, research on transcriptome and genome of schizothoracine fish may contribute to explain the mechanism of their adaption to Tibetan Plateau.

\section{Methods}

\section{Ethics statement}

The experiments were performed in accordance with the Ethics Committee of the Institute of Hydrobiology, Chinese Academy of Sciences. The policies were enacted according to Chinese Association for Laboratory Animal Sciences, and coordinated with the Institutional Animal Care and Use Committee (IACUC) protocols [68,69].

\section{Sampling}

Schizothorax prenanti (primitive schizothoracine fish) and Gymnodiptychus pachycheilus (specialized schizothoracine fish) were collected from Ya'an in Sichuan Province; Gymnocypris eckloni, Schizopygopsis pylzovi, and Platypharodon extremus (highly specialized schizothoracine fish) were collected from the headwaters of the Yellow River; Gymnocypris namensis (highly specialized schizothoracine fish) was collected from Namtso Lake; Danio rerio (AB strain) was collected from Institute of Hydrobiology, Chinese Academy of Sciences. Permissions for extracting the fish were obtained from Aquaculture Bureau of Sichuan Province and Aquaculture Bureau of Qinghai Province. The seven species, which are all the hypoxiatolerant fish, live at different altitudes. The schizothoracine fish cover five genera and three groups. Tissue samples (heart and liver) were obtained and immediately infused with Trizol (TaKaRa) and conserved at $-70^{\circ} \mathrm{C}$ until RNA extraction.

\section{RNA isolation, CDNA synthesis, and sequence amplification}

RNA extraction was performed using the Trizol reagent according to the manufacturer's instructions. The quality of RNA was determined on 1.2\% EtBr-agarose gels, and the quantity $\left(\mathrm{A}_{260} / \mathrm{A}_{280}\right)$ was measured with a UV spectrophotometer (Thermo Scientific Nanodrop 2000).

First, $1 \mu \mathrm{g}$ of total RNA was used to synthesize firststrand cDNA using reverse transcriptase (Promega) in the presence of RNAse inhibitor (Invitrogen) with a cocktail of oligoT and dNTP (TaKaRa). The 5'-RACEready cDNA and 3'-RACE-ready CDNA were synthesized using a SMART ${ }^{\mathrm{TM}}$ RACE cDNA Amplification Kit (ClonTech) and FirstChoice ${ }^{\circledast}$ RLM-RACE Kit (Ambion), respectively. To obtain the intact cDNA, different tissue samples with the best quality RNA were chosen: heart for Schizothorax prenanti, Gymnodiptychus pachycheilus, and Gymnocypris eckloni, and liver for Gymnocypris namensis, Schizopygopsis pylzovi, Platypharodon extremus, and Danio rerio.

Universal primers (Additional file 6: Table S2) for amplifying partial cDNA fragments were designed using the Primer Premier 5 program against the conserved consensus sequences derived from multiple alignment of hif- $1 \alpha A / B$ and hif- $2 \alpha A / B$ sequences from Schizothorax prenanti (Prenant's schizothoracin), Danio rerio (zebrafish), Hypophthalmichthys molitrix (silver carp), and Hypophthalmichthys nobilis (bighead carp), which were collected from Ensembl or National Center for Biotechnology Information (NCBI, Additional file 7: Table S3) [70]. 
First-strand cDNAs were used in the primary PCR amplification with the universal primers. The conditions for PCR amplification were an initial denaturation at $94^{\circ} \mathrm{C}$ for $3 \mathrm{~min}, 25$ cycles of denaturation at $94^{\circ} \mathrm{C}$ for $30 \mathrm{~s}$, annealing at $60^{\circ} \mathrm{C}$ for $30 \mathrm{~s}$, and extension at $72^{\circ} \mathrm{C}$ for $2 \mathrm{~min}$, and a final extension at $72^{\circ} \mathrm{C}$ for $10 \mathrm{~min}$.

The partial sequences obtained with the universal primers were used to design the gene specific primers for $5{ }^{\prime}$ - and $3{ }^{\prime}$-RACE reactions (Additional file 8: Table S4). RACE reactions were performed in accordance with the instructions in a SMART ${ }^{\mathrm{TM}} \mathrm{RACE}_{\mathrm{CDNA}}$ Amplification Kit (ClonTech) and FirstChoice ${ }^{\odot}$ RLM-RACE Kit (Ambion).

All PCR products were detected in $0.8 \%$ EtBr-agarose gels, and bands corresponding to hif fragments were excised and extracted with a DNA Gel Extraction Kit (Tiangen). The sequences were recombined with pMD18-T vector (TaKaRa), sequenced using ABI3730XL sequencer (Beijing Tianyi Huiyuan Bioscience and Technology Inc.), and assembled using SeqMan in DNASTAR Lasergene v7.1 software (DNASTAR Inc.). The assembled sequences were verified using the NCBI database. The full-length sequences of hif- $1 \alpha A / B$ and hif- $2 \alpha A / B$ were amplified using newly designed gene-specific primers to the $5^{\prime}$ and 3 ' ends with the restriction enzyme sites (Additional file 9: Table S5).

\section{Sequence alignment and phylogenetic analysis}

The alignment of the hif- $1 \alpha$ and hif- $2 \alpha$ coding sequences (corresponding to a total of 69 sequences and 3,090 bases pairs obtained after alignment) was based on notional translations of nucleotide sequences using ClustalX [71]. Additionally, the GTR + I (0.0821) + G (1.0813) model was adopted for the phylogeny by running PAUP4.0b10 and modeltest3.7 [72,73]. Finally, Mrbayes-3.1.2 with 2,000,000 iterations and RAxML with 1,000 nonparametric bootstrap replicates were used to construct a phylogenetic tree $[42,43]$. The sequences of sea squirt and amphioxus hif- $\alpha$ were used as outgroups.

\section{Model testing of selection pressures}

To determine whether hif gene paralogs have undergone statistically significant differences in selection pressures, standard branch-site models in codeml software of PAML (version 4.6) and stochastic branch-site models in fitmodel (version 20140407) were used $[48,49,74-78]$. The two methods all employed ML estimates of the ratio of nonsynonymous to synonymous substitutions $\left(d_{\mathrm{N}} / d_{\mathrm{S}}=\omega\right)$ and nested likelihood ratio tests (LRTs) on a phylogeny tree (Additional file 4: Figure S3). In standard branch-site models, only the Cyprinidae species which had all the four paralogs were included, and the clades corresponding to schizothoracine fish were marked as foreground branches.

\section{Recombined plasmid construction}

The correct and intact hif- $1 \alpha$ and hif- $2 \alpha$ genes of Danio rerio, Schizothorax prenanti, Gymnodiptychus pachycheilus, and Gymnocypris eckloni were isolated from one of the TA clones and subcloned into pCMV-Myc vector (CloneTech) using special restriction enzyme sites (Additional file 6: Table S2). All recombined plasmids were verified by DNA sequencing.

\section{Cell culture}

Human embryonic kidney (HEK) 293 T cells were cultured in Dulbecco's modified Eagle's medium (DMEM, Hyclone) supplemented with $10 \%$ fetal bovine serum (FBS, Hyclone) in a $5 \% \mathrm{CO}_{2}$ incubator (Thermo). Hypoxia treatment was conducted in a hypoxia carbon dioxide incubator filled with $1 \% \mathrm{O}_{2}$.

\section{Western blot analysis}

HEK 293 T cells were seeded in 6-well plates for $24 \mathrm{~h}$ before transfection, and then transfected with $1.6 \mu \mathrm{g}$ every plasmid (included empty vector and indicated Myc-tagged HIF- $\alpha$ constructs) using VigoFect (Vigorous). Six hours after transfection, the cells were divided into two groups and cultured under normoxic and hypoxic conditions $\left(1 \% \mathrm{O}_{2}\right)$ for $18 \mathrm{~h}$. Cells were lysed in RIPA buffer (Beyotime) and 1\% PMSF was added (Beyotime). Then the lysate was mixed with $5 \times$ protein loading buffer (Beyotime), and boiled for $5 \mathrm{~min}$. Protein samples were separated using the denaturing electrophoresis on 12\% SDS-polyacrylamide vertical gels and transferred to a PVDF (polyvinylidene fluoride) membrane (Millipore). The membrane was blocked for $2 \mathrm{~h}$ in $5 \%$ nonfat dry milk in TBST (TBS: $7.3 \mathrm{~g} \mathrm{NaCl}$ and $3.03 \mathrm{~g}$ Tris-Base diluted in 1,000 $\mathrm{mL} \mathrm{H}_{2} \mathrm{O}$, TBST: TBS supplemented with $0.1 \%$ Tween 20) at room temperature and incubated with primary antibody (cMyc (9E10), Santa Cruz) that had been diluted 1:3,000 in $1 \%$ nonfat dry milk in TBST for $12 \mathrm{~h}$ at $4^{\circ} \mathrm{C}$. The membrane was washed three times with TBST for $8 \mathrm{~min}$ each and incubated with the secondary antibody (HRPlabeled Goat Anti-Mouse IgG $(\mathrm{H}+\mathrm{L})$, Beyotime) that had been diluted 1:2,000 in 1\% nonfat milk in TBST. The membrane was then washed, and the HIF- $\alpha$ protein was detected using enhanced chemiluminescence (ECL, Millipore) in an ImageQuant ${ }^{\mathrm{Ts}}$ LAS 4000 mini (GE Healthcare). Tubulin was used as the internal control.

\section{Luciferase detection}

HEK 293 T cells were seeded in 24-well plates for $24 \mathrm{~h}$ before transfection and then co-transfected with empty vector (control) or the indicated Myc-tagged HIF- $\alpha$ constructs, the HRE-luciferase reporter (provided by Professor Wuhan Xiao), and the pTK-Renilla luciferase reporter (used as an internal control) using VigoFect (Vigorous). Six hours after 
transfection, the cells were separated into two groups and cultured under normoxic and hypoxic conditions $\left(1 \% \mathrm{O}_{2}\right)$ for $18 \mathrm{~h}$. Luciferase activity was measured using a DualLuciferase Reporter Assay System (Promega).

\section{Additional files}

Additional file 1: Table S1. Lengths of hif sequences.

Additional file 2: Figure S1. Multiple sequence alignment of the deduced HIF-1a protein sequences. Dashes indicate the gaps inserted to facilitate alignment. All of the domains are indicated either inside a solid box or overlining. The two conserved proline residues within the ODD domain are indicated by the closed arrows, and the two conserved proline hydroxylation motif LxxLAP areas are indicated by dotted boxes. The open arrow indicates the asparagine residue (Asn-803 in human hif-1a) in C-TAD which controls HIF-1 binding to CBP/p300.

Additional file 3: Figure S2. Phylogenetic tree constructed for chordate hif- $1 a$ and hif-2a gene. The phylogenetic tree constructed by MrBayes (left, 2,000,000 iterations) and RAxML (right, 1,000 nonparametric bootstrap replicates) with GTR + I (0.0821) + G (1.0813) model. Bayesian posterior probability values and maximum likelihood bootstrap values are indicated beside the branches.

Additional file 4: Figure S3. Phylogenetic tree used to assess selection pressure. A) Phylogeny for standard branch-site models was constructed using concatenated hif- $1 a$ and hif-2a sequences by MrBayes with TVM + $\mathrm{G}(0.4427)$ model $(2,000,000$ iterations). B) The phylogeny for stochastic branch-site models was constructed using hif-1 $a A$ and hif- $1 a B$ sequences by MrBayes with GTR $+\mathrm{G}(0.7121)$ model (2,000,000 iterations).

Additional file 5: Figure S4. Expression of HIF-a in HEK 293 T cells under hypoxic conditions. Generally speaking, there was more HIF-1a expression than that of HIF-2a expression after hypoxic treatment.

Additional file 6: Table S2. Universal primers used in this study. Additional file 7: Table S3. Database ID of the sequences used in this study.

Additional file 8: Table S4. Gene-specific primers for 5'-RACE and 3'-RACE.

Additional file 9: Table S5. Gene-specific primers with restriction enzyme sites for full-length sequences.

\section{Abbreviations}

HIF: Hypoxia-inducible factor; HIE: Hypoxia-inducible enhancer; HRE: Hypoxiaresponse element; bHLH-PAS: Basic helix-loop-helix-per-ARNT-sim; ODDD: Oxygen-dependent degradation domains; TAD: Transactivation activation domain; RACE: Rapid amplification of cDNA ends; PHD: Prolyl-4hydroxylase; VHL: Von-Hippel-Lindau tumor suppressor; NLS: Nuclear localization signal; BEB: Bayes empirical Bayes; LRTs: Likelihood ratio tests; HEK: Human embryonic kidney; DMEM: Dulbecco's modified Eagle's medium; FBS: Fetal bovine serum; SDS: Sodium dodecyl sulfate; PVDF: Polyvinylidene fluoride; ECL: Enhanced chemiluminescence.

\section{Competing interests}

All the authors declare that there have been no competing interests.

\section{Authors' contributions}

Prof. Shunping He proposed the research idea. Dr. Wei Chi collected the fish samples. Dr. Lihong Guan completed most of the experiments and composed the paper. Prof. Wuhan Xiao provided some recombinant plasmids. Prof. Liangbiao Chen revised the paper. All authors read and accepted the final version of the manuscript.

\section{Acknowledgements}

This study was supported by the Pilot projects (Grant No. XDB13020100), the Key Fund and NSFC-Yunnan mutual funds of the National Natural Science Foundation of China (Grant Nos. 31130049 and U1036603). We would like to thank Dr. Stephane Guindon for help in specification of the parameters of stochastic branch-site models and analysis of the results.

\section{Author details}

${ }^{1}$ Institute of Hydrobiology, Chinese Academy of Sciences, Wuhan, Hubei, P. R. China. ${ }^{2}$ University of Chinese Academy of Sciences, Beijing, P. R. China. ${ }^{3}$ College of Fisheries, Huazhong Agricultural University, Wuhan, Hubei, P. R. China. ${ }^{4}$ College of Fisheries and Life Science, Shanghai Ocean University, Shanghai, P. R. China.

Received: 19 May 2014 Accepted: 15 August 2014

Published online: 28 August 2014

\section{References}

1. Bridges CB: The Bar "gene" - a duplication. Science 1936, 83:210-211.

2. Ohno S: Evolution by gene duplication. London, New York: Springer-Verlag Press; 1970.

3. Holland PWH, Garciafernandez J, Williams NA, Sidow A: Gene duplications and the origins of vertebrate development. Development 1994, 125-133.

4. Kasahara M, Hayashi M, Tanaka K, Inoko H, Sugaya K, Ikemura T, Ishibashi T: Chromosomal localization of the proteasome $Z$ subunit gene reveals an ancient chromosomal duplication involving the major histocompatibility complex. P Natl Acad Sci USA 1996, 93(17):9096-9101.

5. Sidow A: Gen(om)e duplications in the evolution of early vertebrates. Curr Opin Genet Dev 1996, 6(6):715-722.

6. Opazo JC, Butts GT, Nery MF, Storz JF, Hoffmann FG: Whole-genome duplication and the functional diversification of teleost fish hemoglobins. Mol Biol Evol 2013, 30(1):140-153.

7. Taylor JS, Van de Peer Y, Braasch I, Meyer A: Comparative genomics provides evidence for an ancient genome duplication event in fish. Philos Trans R Soc Lond B Biol Sci 2001, 356(1414):1661-1679.

8. Amores A, Force A, Yan YL, Joly L, Amemiya C, Fritz A, Ho RK, Langeland J, Prince V, Wang YL, Westerfield M, Ekker M, Postlethwait JH: Zebrafish hox clusters and vertebrate genome evolution. Science 1998, 282(5394):1711-1714.

9. Meyer A, Van de Peer Y: From 2R to 3R: evidence for a fish-specific genome duplication (FSGD). Bioessays 2005, 27(9):937-945.

10. RytKönen KT, Vuori KAM, Primmer CR, Nikinmaa M: Comparison of hypoxiainducible factor-1 alpha in hypoxia-sensitive and hypoxia-tolerant fish species. Comp Biochem Phys D 2007, 2(2):177-186.

11. RytKönen KT, Williams TA, Renshaw GM, Primmer CR, Nikinmaa M: Molecular evolution of the metazoan PHD-HIF oxygen-sensing system. Mol Biol Evol 2011, 28(6):1913-1926.

12. Chi W, Gan XN, Xiao WH, Wang W, He SP: Different evolutionary patterns of hypoxia-inducible factor a (HIF- $a$ ) isoforms in the basal branchesof actinopterygii and sarcopterygii. FEBS Open Bio 2013, 3:479-483.

13. Nikinmaa M, Rees BB: Oxygen-dependent gene expression in fishes. Am J Physiol-Reg / 2005, 288(5):R1079-R1090.

14. Lendahl U, Lee KL, Yang H, Poellinger L: Generating specificity and diversity in the transcriptional response to hypoxia. Nat Rev Genet 2009, 10(12):821-832.

15. Wang GL, Semenza GL: Purification and characterization of hypoxiainducible factor-1. J Biol Chem 1995, 270(3):1230-1237.

16. Semenza GL, Wang GL: A nuclear factor induced by hypoxia Via denovo protein-synthesis binds to the human erythropoietin gene enhancer at a site required for transcriptional activation. Mol Cell Biol 1992, 12(12):5447-5454.

17. Semenza GL: Regulation of mammalian O-2 homeostasis by hypoxiainducible factor 1. Annu Rev Cell Dev Bi 1999, 15:551-578.

18. Kewley RJ, Whitelaw ML, Chapman-Smith A: The mammalian basic helix-loop-helix/PAS family of transcriptional regulators. Int J Biochem Cell B 2004, 36(2):189-204.

19. Kaelin WG, Ratcliffe PJ: Oxygen sensing by metazoans: the central role of the HIF hydroxylase pathway. Mol Cell 2008, 30(4):393-402.

20. RytKönen KT, Akbarzadeh A, Miandare HK, Kamei H, Duan CM, Leder EH, Williams TA, Nikinmaa M: Subfunctionalization of cyprinid hypoxiainducible factors for roles in development and oxygen sensing. Evolution 2013, 67(3):873-882.

21. Semenza GL: Regulation of oxygen homeostasis by hypoxia-inducible factor 1. Physiology 2009, 24(2):97-106.

22. Schofield CJ, Ratcliffe PJ: Oxygen sensing by HIF hydroxylases. Nat Rev Mol Cell Bio 2004, 5(5):343-354.

23. Kaelin GWJ: Proline hydroxylation and gene expression. Annu Rev Biochem 2005, 74:115-128. 
24. Wang $G L$, Jiang BH, Rue EA, Semenza GL: Hypoxia-inducible factor-1 is a basic-helix-loop-helix-Pas heterodimer regulated by cellular 0-2 tension. Proc Natl Acad Sci U S A 1995, 92(12):5510-5514.

25. Forsythe JA, Jiang BH, lyer NV, Agani F, Leung SW, Koos RD, Semenza GL: Activation of vascular endothelial growth factor gene transcription by hypoxia-inducible factor 1. Mol Cell Biol 1996, 16(9):4604-4613.

26. Wiener $C M$, Booth $G$, Semenza $G L$ : In vivo expression of mRNAs encoding hypoxia-inducible factor 1. Biochem Bioph Res Co 1996, 225(2):485-488.

27. Nambu JR, Chen W, Hu S, Crews ST: The drosophila melanogaster similar bHLH-PAS gene encodes a protein related to human hypoxia-inducible factor 1 alpha and drosophila single-minded. Gene 1996, 172(2):249-254.

28. Jiang HQ, Guo R, Powell-Coffman JA: The Caenorhabditis elegans hif-1 gene encodes a bHLH-PAS protein that is required for adaptation to hypoxia. Proc Natl Acad Sci U S A 2001, 98(14):7916-7921.

29. Loenarz C, Coleman ML, Boleininger A, Schierwater B, Holland PH, Ratcliffe PJ, Schofield CJ: The hypoxia-inducible transcription factor pathway regulates oxygen sensing in the simplest animal, trichoplax adhaerens. Embo Rep 2011, 12(1):63-70.

30. Maxwell PH, Wiesener MS, Chang GW, Clifford SC, Vaux EC, Cockman ME, Wykoff CC, Pugh CW, Maher ER, Ratcliffe PJ: The tumour suppressor protein VHL targets hypoxia-inducible factors for oxygen-dependent proteolysis. Nature 1999, 399(6733):271-275.

31. Jaakkola P, Mole DR, Tian YM, Wilson MI, Gielbert J, Gaskell SJ, von Kriegsheim A, Hebestreit HF, Mukherji M, Schofield CJ, Maxwell PH, Pugh CW, Ratcliffe PJ: Targeting of HIF-alpha to the von Hippel-Lindau ubiquitylation complex by O-2-regulated prolyl hydroxylation. Science 2001, 292(5516):468-472.

32. Kallio PJ, Okamoto K, O'Brien S, Carrero P, Makino Y, Tanaka H, Poellinger L: Signal transduction in hypoxic cells: inducible nuclear translocation and recruitment of the CBP/p300 coactivator by the hypoxia-inducible factor-1 alpha. Embo J 1998, 17(22):6573-6586.

33. Luo JC, Shibuya M: A variant of nuclear localization signal of bipartitetype is required for the nuclear translocation of hypoxia inducible factors (1 alpha, 2 alpha and 3 alpha). Oncogene 2001, 20(12):1435-1444.

34. Wang ZF, Yonezawa T, Liu B, Ma T, Shen X, Su JP, Guo SC, Hasegawa M, Liu JQ: Domestication relaxed selective constraints on the Yak mitochondrial genome. Mol Biol Evol 2011, 28(5):1553-1556.

35. Cao WX, Chen YY, WU YF, Zhu SQ: Origin and Evolution of Schizothoracine Fishes in Relation to the Upheaval of the QinghaiXizang Plateau. In Studies on the Period, Amplitude and Type of the Uplift of the Qinghai-Xizang Plateau. Edited by Qinghai-Tibet Plateau Comprehensive Scientific Expedition CAoS. Beijing: Science Press; 1981:118-130.

36. Wu YF, Wu CZ: The Fishes of the Qinghai-Xizang Plateau. Sichuan: Sichuan Publishing House of Science and Technology; 1992.

37. Chen YF, Cao WX: Schizothoracinae. In Fauna Sinica (Osteichthyes: Cypriniformes), Volume 3. Edited by Yue PQ. Beijing: Science Press; 2000:273-388.

38. Li Y, Ren Z, M. Shedlock A: High altitude adaptation of the schizothoracine fishes (cyprinidae) revealed by the mitochondrial genome analyses. Gene 2013, 517:169-178.

39. Guan L-H, Chi W, Xiao W-; Chen L-B, He S-P: Data from analysis of hypoxia-inducible factor alpha polyploidization reveals adaptation to Tibetan plateau in the evolution of schizothoracine fish. BMC Evolutionary Biology 2014.

40. Chowdhury R, McDonough MA, Mecinovic J, Loenarz C, Flashman E, Hewitson KS, Domene C, Schofield CJ: Structural basis for binding of hypoxia-inducible factor to the oxygen-sensing prolyl hydroxylases. Structure 2009, 17(7):981-989.

41. Masson N, Willam C, Maxwell PH, Pugh CW, Ratcliffe PJ: Independent function of two destruction domains in hypoxia-inducible factor-alpha chains activated by prolyl hydroxylation. Embo J 2001, 20(18):5197-5206.

42. Huelsenbeck JP, Ronquist F: MRBAYES: Bayesian inference of phylogenetic trees. Bioinformatics 2001, 17(8):754-755.

43. Stamatakis A: RAxML-VI-HPC: Maximum likelihood-based phylogenetic analyses with thousands of taxa and mixed models. Bioinformatics 2006, 22(21):2688-2690.

44. Lartillot N, Lepage T, Blanquart S: PhyloBayes 3: a Bayesian software package for phylogenetic reconstruction and molecular dating. Bioinformatics 2009, 25(17):2286-2288

45. Massey SE, Churbanov A, Rastogi S, Liberles DA: Characterizing positive and negative selection and their phylogenetic effects. Gene 2008, 418(1-2):22-26.
46. Roje DM: Evaluating the effects of Non-neutral molecular markers on phylogeny inference. Plos One 2014, 9(2).

47. Qi DL, Chao Y, Guo SC, Zhao LY, Li TP, Wei FL, Zhao XQ: Convergent, parallel and correlated evolution of trophic morphologies in the subfamily schizothoracinae from the Qinghai-Tibetan plateau. Plos One 2012, 7(3).

48. Yang ZH: PAML 4: phylogenetic analysis by maximum likelihood. Mol Biol Evol 2007, 24(8):1586-1591.

49. Guindon S, Rodrigo AG, Dyer KA, Huelsenbeck JP: Modeling the sitespecific variation of selection patterns along lineages. Proc Natl Acad Sci U S A 2004, 101(35):12957-12962.

50. Soitamo AJ, Rabergh CMI, Gassmann M, Sistonen L, Nikinmaa M: Characterization of a hypoxia-inducible factor (HIF-1 alpha) from rainbow trout - accumulation of protein occurs at normal venous oxygen tension. J Biol Chem 2001, 276(23):19699-19705.

51. Powell WH, Hahn ME: Identification and functional characterization of hypoxia-inducible factor 2 alpha from the estuarine teleost, Fundulus heteroclitus: Interaction of HIF-2 alpha with two ARNT2 splice variants. J Exp Zool 2002, 294(1):17-29.

52. Law SHW, Wu RSS, Ng PKS, Yu RMK, Kong RYC: Cloning and expression analysis of two distinct HIF-alpha isoforms - gcHIF-1alpha and gcHIF4alpha - from the hypoxia-tolerant grass carp, ctenopharyngodon idellus. Bmc Mol Biol 2006, 7(15).

53. Rissanen E, Tranberg HK, Sollid J, Nilsson GE, Nikinmaa M: Temperature regulates hypoxia-inducible factor-1 (HIF-1) in a poikilothermic vertebrate, crucian carp (Carassius Carassius). J Exp Biol 2006, 209(6):994-1003.

54. Rahman MS, Thomas P: Molecular cloning, characterization and expression of two hypoxia-inducible factor alpha subunits, HIF-1 alpha and HIF-2 alpha, in a hypoxia-tolerant marine teleost, Atlantic croaker (Micropogonias undulatus). Gene 2007, 396(2):273-282.

55. Rojas DA, Perez-Munizaga DA, Centanin L, Antonelli M, Wappner P, Allende $M L$, Reyes AE: Cloning of hif-1 alpha and hif-2 alpha and mRNA expression pattern during development in zebrafish. Gene Expr Patterns 2007, 7(3):339-345

56. Cao YB, Chen XQ, Wang S, Wang YX, Du JZ: Evolution and regulation of the downstream gene of hypoxia-inducible factor-1 alpha in naked carp (gymnocypris przewalskii) from lake Qinghai, china. J Mol Evol 2008, 67(5):570-580.

57. Shen RJ, Jiang XY, Pu JW, Zou SM: HIF-1 alpha and -2 alpha genes in a hypoxia-sensitive teleost species megalobrama amblycephala: cDNA cloning, expression and different responses to hypoxia. Comp Biochem Phys B 2010, 157(3):273-280.

58. Chen N, Chen LP, Zhang J, Chen C, Wei XL, Gul Y, Wang WM, Wang HL: Molecular characterization and expression analysis of three hypoxiainducible factor alpha subunits, HIF-1 alpha/2 alpha/3 alpha of the hypoxia-sensitive freshwater species, Chinese sucker. Gene 2012, 498(1):81-90.

59. Beall CM, Cavalleri GL, Deng LB, Elston RC, Gao Y, Knight J, Li CH, Li JC, Liang Y, McCormack M, Montgomery HE, Pan H, Robbins PA, Shianna KV Tam SC, Tsering N, Veeramah KR, Wang W, Wangdui PC, Weale ME, Xu YM, Xu Z, Yang L, Zaman MJ, Zeng CQ, Zhang L, Zhang XL, Zhaxi PC, Zheng YT: Natural selection on EPAS1 (HIF2 alpha) associated with low hemoglobin concentration in Tibetan highlanders. Proc Natl Acad Sci U S A 2010, 107(25):11459-11464.

60. Yi X, Liang Y, Huerta-Sanchez E, Jin X, Cuo ZXP, Pool JE, Xu X, Jiang H, Vinckenbosch N, Korneliussen TS, Zheng HC, Liu T, He WM, Li K, Luo RB, Nie XF, Wu HL, Zhao MR, Cao HZ, Zou J, Shan Y, Li SZ, Yang Q, Asan, Ni PX, Tian G, Xu JM, Liu XA, Jiang T, Wu RH: Sequencing of 50 human exomes reveals adaptation to high altitude. Science 2010, 329(5987):75-78.

61. Qiu Q, Zhang GJ, Ma T, Qian WB, Wang JY, Ye ZQ, Cao CC, Hu QJ, Kim J, Larkin DM, Auvil L, Capitanu B, Ma J, Lewin HA, Qian XJ, Lang YS, Zhou R, Wang LZ, Wang K, Xia JQ, Liao SG, Pan SK, Lu X, Hou HL, Wang Y, Zang XT, Yin Y, Ma H, Zhang J, Wang ZF: The yak genome and adaptation to life at high altitude. Nat Genet 2012, 44(8):946-949.

62. Ge RL, Cai QL, Shen YY, San A, Ma L, Zhang Y, Yi X, Chen Y, Yang LF, Huang Y, He RJ, Hui YY, Hao MR, Li Y, Wang B, Ou XH, Xu JH, Zhang YF, Wu K, Geng CY, Zhou WP, Zhou TC, Irwin DM, Yang YZ, Ying L, Bao HH, Kim J, Larkin DM, Ma J, Lewin HA: Draft genome sequence of the Tibetan antelope. Nat Commun 2013, 4.

63. Qu YH, Zhao HW, Han NJ, Zhou GY, Song G, Gao B, Tian SL, Zhang JB, Zhang RY, Meng XH, Zhang Y, Zhang Y, Zhu XJ, Wang WJ, Lambert D, 
Ericson PGP, Subramanian S, Yeung C, Zhu HM, Jiang Z, Li RQ, Lei FM: Ground tit genome reveals avian adaptation to living at high altitudes in the Tibetan plateau. Nat Commun 2013, 4.

64. Li Y, Wu DD, Adam RB, Wang GD: Population variation revealed high altitude adaptation of Tibetan mastiffs. Mol Biol Evol 2014, 31(5):1200-1205.

65. Gao S, Lu L, Bai Y, Zhang P, Song WB, Duan CM: Structural and functional analysis of amphioxus HIF alpha reveals ancient features of the HIF alpha family. Faseb J 2014, 28(4):1880-1890.

66. Pugh CW, ORourke JF, Nagao M, Gleadle JM, Ratcliffe PJ: Activation of hypoxia-inducible factor-1; Definition of regulatory domains within the alpha subunit. J Biol Chem 1997, 272(17):11205-11214.

67. Semenza GL: HIF-1: mediator of physiological and pathophysiological responses to hypoxia. J Appl Physiol 2000, 88(4):1474-1480.

68. Chinese association for laboratory animal sciences. [http://www.calas.org. $\mathrm{cn} / \mathrm{htm} /$ /jypx/zcfg/]

69. Institutional animal care and Use committee. [http://iacuc.usc.edu/]

70. Lalitha S: Primer premier 5. Biotech software \& Internet Report 2000, 1(6):270-272.

71. Larkin MA, Blackshields G, Brown NP, Chenna R, McGettigan PA, McWilliam H, Valentin F, Wallace IM, Wilm A, Lopez R, Thompson JD, Gibson TJ, Higgins DG: Clustal W and clustal X version 2.0. Bioinformatics 2007, 23(21):2947-2948.

72. Posada D, Crandall KA: MODELTEST: testing the model of DNA substitution. Bioinformatics 1998, 14(9):817-818.

73. Swofford DL: PAUP*: phylogenetic analysis using parsimony, version 4.0b10. 2003.

74. Anisimova M, Yang ZH: Multiple hypothesis testing to detect lineages under positive selection that affects only a few sites. Mol Biol Evol 2007, 24(5):1219-1228

75. Lu A, Guindon S: Performance of standard and stochastic branch-site models for detecting positive selection among coding sequences. Mol Biol Evol 2014, 31(2):484-495.

76. Yang ZH, Nielsen R: Codon-substitution models for detecting molecular adaptation at individual sites along specific lineages. Mol Biol Evol 2002, 19(6):908-917.

77. Yang ZH, Wong WSW, Nielsen R: Bayes empirical Bayes inference of amino acid sites under positive selection. Mol Biol Evol 2005, 22(4):1107-1118

78. Zhang JZ, Nielsen R, Yang ZH: Evaluation of an improved branch-site likelihood method for detecting positive selection at the molecular level. Mol Biol Evol 2005, 22(12):2472-2479.

79. National geographic ArcMap esri db. [http://education.nationalgeographic com/education/mapping/interactive-map/?ar_a $=1$ ]

doi:10.1186/s12862-014-0192-1

Cite this article as: Guan et al: Analysis of hypoxia-inducible factor alpha polyploidization reveals adaptation to Tibetan plateau in the evolution of schizothoracine fish. BMC Evolutionary Biology 2014 14:192.

\section{Submit your next manuscript to BioMed Central and take full advantage of:}

- Convenient online submission

- Thorough peer review

- No space constraints or color figure charges

- Immediate publication on acceptance

- Inclusion in PubMed, CAS, Scopus and Google Scholar

- Research which is freely available for redistribution 